\title{
Optimalisasi pembelajaran virtual melalui workshop penggunaan aplikasi Microsoft teams di SMP Unismuh Makassar dan SMA Unismuh Makassar
}

\section{Sitti Rahmah Tahir ${ }^{1}$, St.Nur Humairah Halim ${ }^{2 *}$, Randy Saputra Mahmud ${ }^{3}$, Sri Satriani ${ }^{4}$}

1,2,3,4 Pendidikan Matematika, FKIP, Universitas Muhammadiyah, Makassar

*humairah@unismuh.ac.id.

\begin{abstract}
This workshop on using the Microsoft teams application aims to help teachers at school Unismuh Junior High School in Makassar and Unismuh Senior High Schoolin Makassar can further optimize learning virtual during the pandemic and after the pandemic, so that not only the professional competence of teachers in the IT field can increase but can also motivate students to be more motivated to improve their learning achievements, in addition to the features of Microsoft teams, project-based learning during this period pandemic and after the pandemic can be done more interactively. The method used in this implementation is training as well as mentoring, where the steps taken are (1) providing material about Microsoft development and introduction to Microsoft teams features using lecture and quiz methods, (2) training on the use of Microsoft teams in providing learning materials and assignments to students, and (3) mentoring and discussions with resource persons about the use of Microsoft teams in the subjects taught by each teacher.
\end{abstract}

Keywords: workshop; virtual learning; Microsoft teams

\begin{abstract}
Abstrak
Workshop penggunaan aplikasi Microsoft teams ini bertujuan untuk membantu guru-guru disekolah SMP Unismuh Makassar dan SMA Unismuh Makassar agar dapat lebih mengoptimalkan pembelajaran virtual selama masa pandemi dan setelah pandemi, sehingga tidak hanya kompetensi professional guru dalam bidang IT yang meningkat tapi juga dapat memotivasi siswa-siswinya agar lebih termotivasi untuk meningkatkan prestasi belajarnya, selain itu dengan adanya fitur-fitur dari Microsoft teams maka pembelajaran berbasis proyek selama masa pandemi maupun setelah pandemi dapat dilakukan dengan lebih interaktif. Metode yang digunakan dalam pelaksanaan ini adalah pelatihan sekaligus pendampingan, dimana langkah-langkah yang dilakukan adalah (1) pemberian materi tentang perkembangan Microsoft dan pengenalan fitur-fitur Microsoft teams menggunakan metode ceramah dan kuis, (2) pelatihan penggunaan Microsoft teams dalam memberikan materi pembelajaran dan penugasan kepada peserta didik, dan (3) pendampingan dan diskusi dengan narasumber tentang penggunaan Microsoft teams pada mata pelajaran yang diampuh masing-masing guru.
\end{abstract}

Kata Kunci: workshop; pembelajaran virtual; Microsoft teams

\section{PENDAHULUAN}

Sejak covid-19 dinyatakan sebagai pandemi pada tahun 2019, maka berbagai sektor kehidupan manusia seakan lumpuh. Kasus dari pandemi tersebut mulai meningkat 
sekitar pertengahan tahun 2020 di Indonesia sehingga membuat keputusan pemerintah RI untuk melakukan PSBB (Pembatasan Sosial Berskala Besar) di kota-kota besar tanpa terkecuali di Kota Makassar. Adapun salah satu sektor yang paling terdampak dari keputusan tersebut adalah sektor pendidikan.

Sejak PSBB diberlakukan, sekolah dituntut untuk melakukan transformasi pembelajaran dari tatap muka dalam kelas menjadi pembelajaran secara virtual. Awalnya pembelajaran dengan menggunakan aplikasi media sosial grup whatsApp lalu berkembang menggunakan google classroom, zoom meeting, google meet, edmodo, quipper, bahkan youtube. Pemilihan aplikasi-aplikasi tersebut dipengaruhi oleh kebutuhan guru maupun murid agar dapat berinteraksi secara optimal meskipun secara virtual. Namun, aplikasi tersebut dirasa masih memiliki kekurangan oleh guru, termasuk guru-guru di sekolah mitra. Hal tersebut ditunjukkan dari hasil observasi berupa wawancara singkat dengan beberapa guru disekolah mitra pada tanggal 10 April 2021, diperoleh informasi bahwa guru-guru telah beberapa kali mengganti aplikasi yang dipakai untuk pembelajaran online, awalnya adalah Edmodo, namun belum begitu ditekuni karena masih memungkinkan untuk tatap muka, kemudian berganti ke classroom untuk pengecekan tugas, tetapi aplikasi tersebut terbatas pada penggunaan simbol matematika dan karakter bahasa Arab. Selain itu, guru juga telah menggunakan Nuadu dan Zoom meeting namun cukup menguras banyak kuota internet.

Berdasarkan analisis situasi dan permasalahan mitra, maka persoalan prioritas yang disepakati bersama mitra sasaran dalam PKM ini adalah guru-guru di SMP Muhammadiyah dan SMA Unismuh Makassar membutuhkan pelatihan penggunaan aplikasi yang tepat sebagai media dalam pembelajaran, membutuhkan pelatihan merancang pembelajaran menggunakan aplikasi, serta mitra sasaran perlu meningkatkan kompetensinya dalam pembelajaran berbasis aplikasi pembelajaran daring.

Menurut Mu'ti (2020) Berdasarkan Surat Edaran dari Kemendikbud, berikut 8 aplikasi yang bisa membantu pada saat proses pembelajaran daring, yaitu: 1) Rumah Belajar, 2) Google G Suites for Education, 3) Kelas Pintar, 4) Microsoft Office 365, 5) Quipper School, 6) Sekolah Online Ruang Guru, 7) Sekolahmu, dan 8) Zenius. Dan diantara 8 aplikasi tersebut yang mudah dipelajari dan mempunyai fitur yang lengkap untuk melaksanakan pembelajaran adalah Microsoft Office 365.

Selanjutnya menurut Amirullah \& Maesaroh (2020), Microsoft office 365 dapat memudahkan pendidik untuk berbagi dan berkolaborasi dalam hal dokumen pembelajaran, serta mendukung proses maupun evaluasi pembelajaran daring yang memanfaatkan koneksi internet. Microsoft office 365 merupakan aplikasi office cloud dari Microsoft yang memungkinkan penggunanya untuk mengakses dan berbagi konten secara daring dengan bantuan internet secara fleksible yang dapat digunakan pada berbagai jenis gadget seperti smartphone atau komputer. 
Sedangkan Aziizah et al., (2020) menjelaskan bahwa teknologi ini mengizinkan para pengguna untuk menjalankan program tanpa instalasi dan mengizinkan pengguna utuk mengakses data pribadi mereka melalui komputer dengan akses internet, dalam office 365 ada beberapa program berbasis cloud yang antara lain adalah: Outlook, One Drive,Word, Excel, Power Point, One Note, Share Point, Teams, Classnote, Sway dan Form.

Untuk fitur Outlook, Word, Excel,Power Point, dan One Note ini sudah sangat familiar digunakan pada Microsoft office versi pendahulunya, namun yang menjadi fitur kebutuhan paling utama dalam pembelajaran virtual yakni classroom tools, yang terdiri dari Microsoft Teams, OneNote Class Notebook, dan Sway. Di antara ketiganya yang paling popular digunakan dikalangan pendidik belakangan ini adalah Microsoft Teams karena fitur yang digunakan dalam Microsoft teams sangat bervariasi dan tentu saja memiliki lebih banyak kelebihan. Menurut Saputra \& Saddhono (2021) tentang beberapa fitur Microsoft Office Teams 365 yang dapat digunakan dalam pembelajaran yaitu fitur office word dapat digunakan untuk menyusun perangkat pembelajaran, office excel dapat digunakan untuk melakukan penilaian, office power point dapat digunakan untuk menampilkan materi ajar, office forms dapat digunakan untuk menyusun soal dan kuesioner, ruang chatting dapat digunakan oleh guru untuk berinteraksi dengan siswa, Microsoft Teams dapat digunakan untuk memantau aktivitas siswa dalam pembelajaran virtual.

Telah banyak hasil penelitian mengenai Microsoft Teams yang digunakan sebagai media dalam pembelajaran. Menurut Situmorang (2020) pembelajaran menggunakan Microsoft Teams sangat baik untuk meningkatkan minat belajar peserta didik. Selain itu, menurut Widiyarso \& Sutama (2021) Microsoft Teams memiliki efektifitas tinggi dalam penyelenggaraan pembelajaran berbasis e-learning.

Berdasarkan keunggulan dari Microsoft Teams inilah, maka tim PKM berusaha untuk memberikan solusi atas permasalahan-permasalahan yang dihadapi guru-guru disekolah mitra dengan melaksanakan pelatihan dan pendampingan melalui kegiatan "Optimalisasi Pembelajaran Virtual Melalui Workshop Penggunaan Aplikasi Microsoft teams Di SMP Unismuh Makassar Dan SMA 1 Unismuh Makassar”.

\section{METODE PELAKSANAAN}

Metode yang digunakan dalam pelaksanaan ini adalah pelatihan sekaligus pendampingan, dimana kegiatan pengabdian kepada masyarakat ini dilaksanakan di lingkup kampus Universitas Muhammadiyah Makassar, yang lokasinya satu lingkup dengan kedua sekolah mitra. Metode pelaksanaan kegiatan berupa: (1) pemberian materi tentang perkembangan Microsoft dan pengenalan fitur-fitur Microsoft teams menggunakan metode ceramah dan tanya jawab, (2) pelatihan penggunaan Microsoft teams dalam memberikan materi pembelajaran dan penugasan kepada peserta didik, (3) pendampingan dan diskusi dengan narasumber tentang penggunaan Microsoft teams pada mata pelajaran yang diampuh masing-masing guru dan (4) Pengaplikasian 
Microsoft teams pada pembelajaran di kelas yang diampuh masing-masing guru diluar daripada waktu pelaksanaan workshop yang dibuktikan dengan dokumentasi sebagai tolak ukur kegiatan PKM ini telah terlaksana dengan optimal. Pelaksanaan kegiatan ini melibatkan dua sekolah mitra, yakni SMA 1 Unismuh Makassar dan SMP 1 Unismuh Makassar yang keduanya berada di lokasi yang sama dalam kampus Unismuh Makassar. Karena kegiatan ini berlangsung di saat pandemic maka kegiatan ini hanya diikuti perwakilan dari masing-masing sekolah yang terdiri dari 20 peserta yakni 10 orang guru SMP 1 Unismuh Makassar dan 10 orang guru SMA 1 Unismuh Makassar. Kegiatan ini dilaksanakan pada tanggal 12 Juni 2021 dengan memilih ruangan PPG II FKIP Lantai II Unismuh Makassar, karena ruangan ini dianggap cukup untuk menampung peserta dengan jumlah sedikit dan ruangan ini pula telah terfasilitasi dengan koneksi Wifi, adanya sound system dan LCD.

\section{HASIL DAN PEMBAHASAN}

Pelaksanaan pengabdian kepadamasyarakat dilaksanakan pada hari Sabtu, 12 Juni 2021.Tempat kegiatan berada diruangan PPG II FKIP Lantai II Unismuh Makassar, Jl. Sultan Alauddin No.259, Makassar. Kegiatan pengabdian kepada masyarakat dimulai dengan registrasi peserta pada pukul 08.00-08.30 WITA dan kegiatan ini telah dijalankan dari awal dengan mematuhi protokol kesehatan.

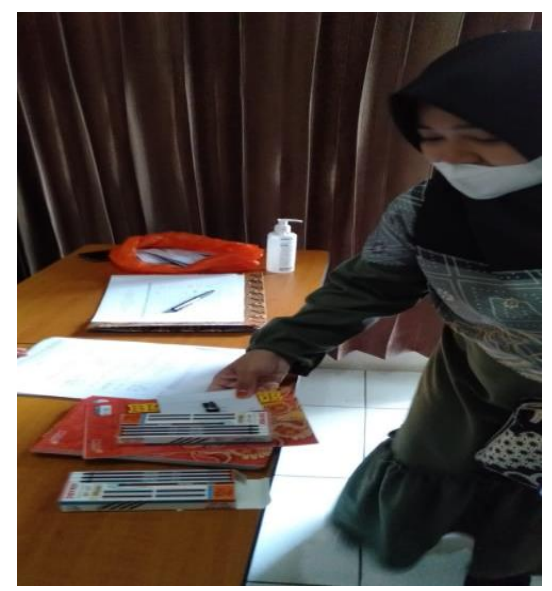

Gambar 1. Proses registrasi peserta

Pelaksanaan pengabdian dimulai pukul 08.35 dan dibuka dengan sambutan dari sekertaris LP3M. Dalam sambutannya, beliau menyampaikan apresiasi kepada tim PKM karena melaksanakan kegiatan yang sangat sesuaidengan kebutuhan guru-guru. Beliau berharap agar pengabdian seperti ini terus dapat dilaksanakan dengan menjalin kerjasama dengan sekolah-sekolah mitra agar kemampuan guru-guru dalam bidang IT meningkat, utamanya dalam mengoptimalkan pembelajaran selama masa pandemi ini. Kemudian, acara selanjutnya adalah sambutan yang disampaikan ketua pelaksana kegiatan, yang membahas tentang apa yang memotivasi tim PKM untuk melaksanakan kegiatan pengabdian dan harapan setelah diadakannya kegiatan pengabdian pada 
pukul 09.00. Setelah sambutan-sambutan, sebelum ke kegiatan ini, tidak lupa sesi pembacaan doa pun dilaksanakan.

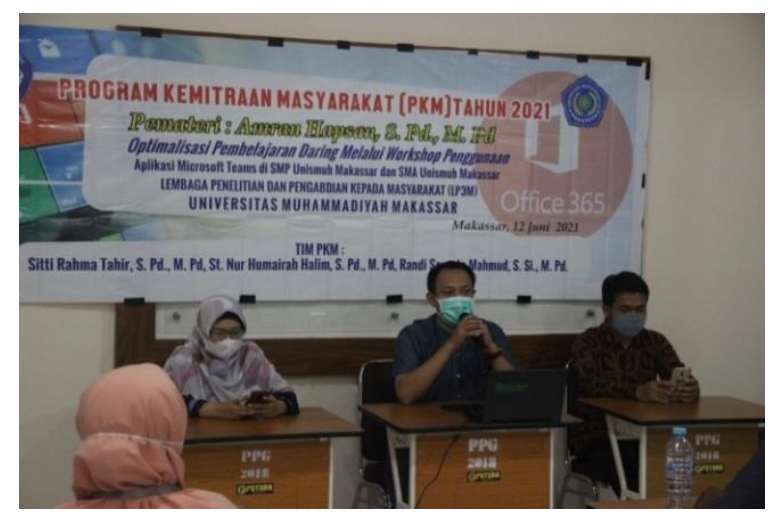

Gambar 2. Pembukaan kegiatan PKM

Pada pukul 09.15, Bapak Amran Hapsan, S.Si., S.Pd., M.Pd. selaku pemateri memulai materi pertama. Adapun materi pertama yang dipaparkan beliau adalah pengenalan microsoft teams dan pengaplikasiannya dalam pembelajaran. Dalam materinya, Bapak Amranmenyampaikan tentang perkembangan microsoft office, ragam pilihan pemanfaat microsoft office terbaru, dan khususnya bagaimana menggunakan fitur-fitur yang tersedia untuk memaksimalkan pembelajaran virtual. Menurut beliau sendiri, karena ini adalah pelatihan pemanfaatan aplikasi jadi lebih efektif jika sambil mendengarkan materi langsung juga pendampingan, sehingga tim PKM dan panitia juga ikut mendampingi guru-guru saat materi pertama disampaikan. Peserta terlihat begitu antusias dan merespons dengan baik setiap arahan yang diberikan pemateri. Sesi pertama ini diakhiri pada jam 12.00 dan mempersilahkan peserta untuk istirahat, solat, dan makan siang sebelum materi kedua dimulai.

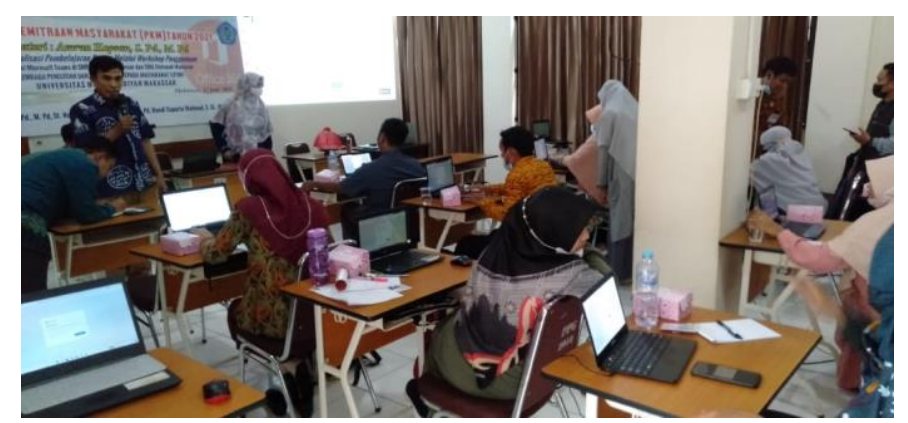

Gambar 3. Pelatihan dan pendampingan peserta

Selanjutnya, sesi kedua kegiatan dimulai pada pukul 13.00 dengan materi penggunaan microsft teams dalam melaksanakan evaluasi pembelajaran yang dipaparkan pula oleh Bapak Amran, menurut beliau pelaksanaan evaluasi semakin efektif dengan menggunakan microsoft teams karena karena aplikasi LMS ini telah berbasis cloud, jadi data dapat disinkronkan dari satu lokasi dengan lokasi lainnya dan otomatis lebih memudahkan guru-guru karena microsoft teams ini merupakan bawaan dari microsoft office 365 sehingga jika ingin memberikan evaluasi dengan menggunakan power point, word, atau excel misalnya itu tidak perlu keluar dari aplikasi, lalu mengupload file, 
memberikan instruksi dan sebagainya, semuanya bisa langsung dilaksanakan di satu aplikasi. Pada tahap ini pun, peserta begitu antusias dan aktif bertanya kepada pemateri terkait solusi dari kendala-kendala saat memberikan evaluasi kepada peserta didik mereka. Kegiatan pada sesi kedua ini diakhiri pada pukul 15.00 dan mempersilahkan peserta menikmati waktu coffe break dan solat. Kegiatan dilanjutkan kembali pada pukul 16.00 yang merupakan sesi terakhir yang merupakan sesi pendampingan, pada sesipendampingan ini tidak ada lagi materi yang dipaparkan, hanya sekedar pemantapan hasil kerja yang dibuat masing-masing guru dengan menggunakan microsoft teams baik dalam pemanfaatannya pada saat merencanakan dan melaksanakan pembelajaran maupun saat melakukan evaluasi pembelajaran. Selain itu, di akhir sesi ini, tim PKM meminta perwakilan dari masing- masing sekolah mitra untuk mempresentasikan hasil karyanya dan bagaimana tahapan untuk memperolehnya, kemudian langsung diberikan tanggapan oleh narasumber. Kegiatan ini berakhir pada pukul 17.00 dan dilanjutkan dengan penutupan kegiatan serta pembagian sertifikat kegiatan kepada para peserta.

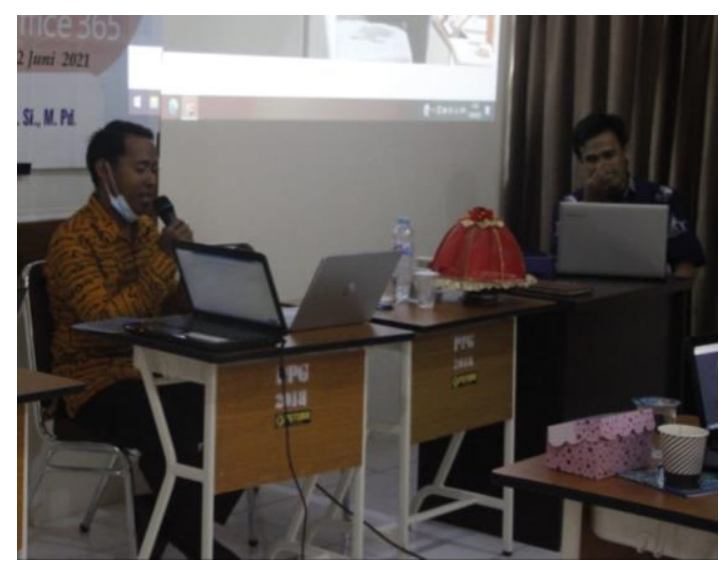

Gambar 4.Presentasi hasil karya peserta

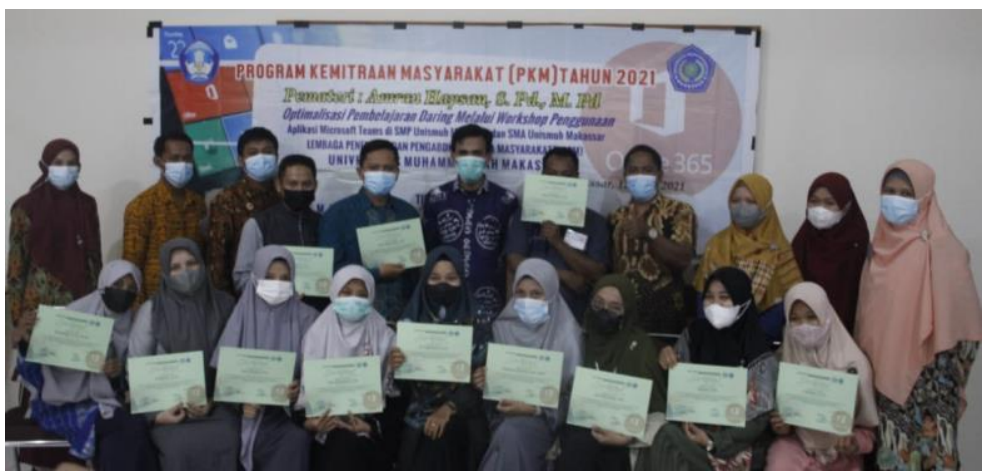

Gambar 5. Pemberian sertifikat peserta

Adapun untuk menilai lebih lanjut keberlangsungan dari kegiatan ini dan menjadi tolok ukur bahwa kegiatan PKM ini mencapai hasil yang optimal, maka kami meminta guru-guru untuk mengaplikasikan ilmu yang diperoleh dari kegiatan PKM ini ke dalam 
pembelajaran yang riil pada mata pelajaran yang diampuh masing-masing guru di sekolah, kemudian mengirimkan kepada kami bukti keterlaksanaannya.

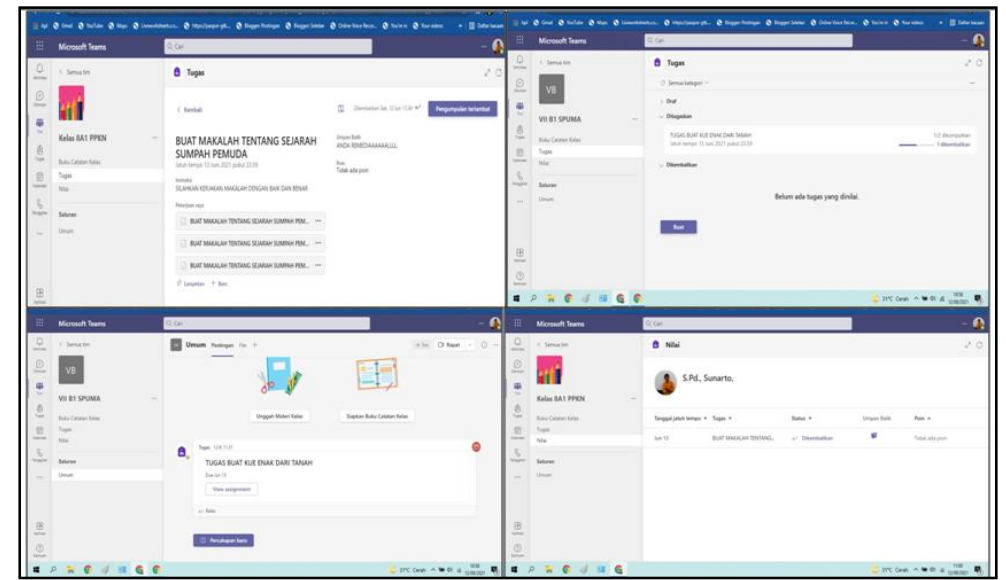

Gambar 6. Bukti keberlanjutan penggunaan Microsoft Teams di sekolah mitra

\section{SIMPULAN}

Meningkatkan kompetensi profesional dengan mengasah skill dalam bidang IT merupakan salah satu kewajiban tenaga pendidik selain mengajar dalam mentransfer informasi dan ilmu pengetahuan, sebab dengan kompetensi profesional yang mumpuni, diharapkan dapat lebih mengoptimalkan pembelajaran sehingga outcome yang diperoleh dari peserta didik pun semakin lebih baik pula. Oleh karena itu, kegiatanpengabdian kepada masyarakat berjudul "Optimalisasi Pembelajaran Virtual Melalui Workshop Penggunaan Aplikasi Microsoft teams Di SMP Unismuh Makassar Dan SMA Unismuh Makassar" mendapatkan apresiasi yang sangat baik oleh pihak sekolah mitra dan peserta, selain itu kegiatan PKM ini telah terlaksana dengan baik dan memperoleh hasil yang optimal, terlihat dari antusias peserta yang tinggi selama workshop berlangsung dan ilmu yang diterima selama workshop kepada kelas yang diampuh masing-masing guru telah mampu diaplikasikan dengan baik. Bahkan beberapa peserta meminta secara langsung untuk mengadakan kembali kegiatan serupa di kesempatan lain.

\section{UCAPAN TERIMA KASIH}

Ucapan terima kasih pertama kami sampaikan kepada para stake holder Universitas Muhammdiyah Makassar selaku institusi yang kami cintai dan banggakan karena bersedia menggelontorkan dana penelitian yang begitu besar untuk memotivasi dosendosennya mengoptimalkan pelaksanaan tri darma perguruan tinggi. Selanjutnya, ucapan terima kasih kami sampaikan kepada pihak LP3M karena telah bersedia memberikan kami kesempatan dan amanah untuk menjalankan kegiatan PKM ini. Tak lupa pula ucapan terima kasih kepada Fakultas FKIP dan prodi pendidikan matematika atas dukungan dan kontribusinya sehingga kegiatan PKM ini dapat 
berjalan dengan baik. Terakhir, ucapan terima kasih kami ucapkan kepada kedua sekolah mitra yakni, SMP Unismuh Makassar dan SMA Unismuh Makassar karena telah bersedia menjadi mitra dan mengikuti sepenuhnya tahapan kegiatan dengan sangat baik.

\section{REKOMENDASI}

Kami merekomendasikan bagi yang ingin melaksanakan kegiatan pengabdian serupa, agar terlebih dahulu melakukan obervasi secara berkala akan kesiapan email institusi sekolah yang dijadikan mitra, sebab email institusi sekolah merupakan syarat mutlak bagi guru dan siswa untuk bisa menggunakan microsoft teams secara fleksibel tanpa terkendala dalam menggunakan berbagai fitur yang tersedia.

\section{REFERENSI}

Amirullah, G., \& Maesaroh, M. (2020). Pelatihan pengembangan kelas digital berbasis microsoft 365 di sekolah Muhammadiyah DKI Jakarta. Community Development Journal: Jurnal Pengabdian Masyarakat, 1(3), 223-227.

Aziizah, A., Sakti, T. B., \& Andriyanto, A. (2020). Pengaruh pembelajaran daring mata pelajaran sejarah melalui microsoft office 365. Keraton: Journal of History Education and Culture, $2(2)$.

Mu'ti, Y. A. (2020). Efektivitas pembelajaran online dengan microsoft teams pada pelajaran matematika materi program linear. EDUKASIA: Jurnal Pendidikan Dan Pembelajaran, 1(2), 347-358.

Saputra, A. D., \& Saddhono, K. (2021). Pembelajaran bahasa indonesia menggunakan Microsoft Office Team 365 untuk SMA di masa pandemi. LINGUA: Jurnal Bahasa, Sastra, Dan Pengajarannya, 18(1), 16-26.

Situmorang, A. S. (2020). Microsoft teams for education sebagai media pembelajaran interaktif meningkatkan minat belajar. Sepren, 2(1), 30.

Widiyarso, T. H., \& Sutama, S. (2021). Efektifitas penggunaan Microsoft Teams dalam pembelajaran e-learning bagi guru selama pandemi Covid-19. Didaktis: Jurnal Pendidikan Dan Ilmu Pengetahuan, 21(1). 